\title{
IDENTIFICATION OF INABILITY STATES OF ROTATING SUBSYSTEMS OF VEHICLES AND MACHINES
}

\author{
Michał Pająk \\ University of Technology and Humanities in Radom \\ Department of Thermal Technology \\ Stasieckiego Street 54, 26-600 Radom, Poland \\ tel.: +48483617149 \\ e-mail:m.pajak@uthrad.pl \\ Dragutin Lisjak, Davor Kolar \\ University of Zagreb \\ Faculty of Mechanical Engineering and Naval Architecture \\ Ivana Lučića Street 5, 10002 Zagreb, Croatia \\ tel.: +385016168377, +385016168308 \\ e-mail:dragutin.lisjak@fsb.hr,dkolar@fsb.hr
}

\begin{abstract}
One of the most important subsystems of the vehicles and machines operating currently in industry and transportation are the rotating subsystems. During the subsystems operation, due to the forcing factors influence, the technical state of them is changing and the failure can occur. In order to avoid such a situation the technical state should be identified online. To do this the analysis of the subsystems vibrations is performed. The identified technical state should be considered in a context of the ability and different inability states. Therefore, the first step of the diagnostic procedure is the ability and different inability states identification. In the article, it is proposed to accomplish this goal by the vibrations analysis in time domain. The described research started with the vibration signals acquisition using the experimental stand. In this way, the vibration signals for ability and different inability states were obtained. Afterwards, the signals were divided into learning and testing data sets. For each signal from learning data set, several characteristics were calculated, and they selected the most significant among them. Using the selected characteristics, the signals from the testing data set were analysed. Thanks to it, the testing vibrations signals were counted among the signals collected on the rotating subsystem operating in ability or selected inability state. The result of the performed studies and the accuracy of the technical state of the tested system identification can be found at the end of the article.
\end{abstract}

Keywords: rotating system, technical state, inability state, ability state, vibration signal, diagnostics, time domain analyse

\section{Introduction}

Rotating subsystems are one of the most important elements used in different kind of vehicles and machines in order to transform the energy and transmit the power. Failures of the rotating subsystems operation are caused by the impact of external forces, fatigue corrosion, aging and inappropriate working conditions. It is a reason of unexpected breakdowns of the production and transportation systems and enormous costs of the systems maintenance. Therefore, monitoring of the technical state of machine and transportation systems is an important issue of the engineering and academic research. Fault detection and rotor systems diagnosis, based on vibration signal analysis, is one of the principal maintenance tools [8]. In term of a system reliability and safety, vibrations are primary diagnostic symptoms [10, 11, 16-18].

Vibrations and noise produced by rotational subsystems occur, practically in all mechanical subsystems of transport means. Vibrations are produced by shafts, axes, fans, pumps and turbines 
depending on the type of transport means or device.

According to literature, it is possible to carry out research on the basis of a correlation analysis and identify early symptoms of rotational system dynamic changes, especially their misalignment, through measurement of its vibrations [2-5, 7]. The Fourier transformation [1,9] and wavelet transformation $[13,14]$ have been widely applied in recognizing the fault feature frequencies of machinery equipment. However, the feature frequency cannot always be detected because of difficulties in obtaining the value of rotating frequency or the values of operational parameters of mechanical parts, which limits its implementation.

The authors focused their efforts on vibration signals time-domain analysis. Firstly, using the simulation stand, the experiment simulations described in chapter 2 were performed in order to record vibration signals of rotational subsystem operating in ability and different inability states. Subsequently, for each signal, several time-domain characteristics were calculated and the most significant of them were selected. They were used to formulate the space of reliability states and the space of inability states. It was described in chapter 3 . In chapter 4 , the implementation of the formulated spaces in order to identify the inability states of the rotational subsystems was presented. The article is summed up by some conclusions formulated in chapter 5 .

\section{Performed experiment simulations}

In the study, the vibration signals acquired from a machine fault simulator were used. A SpectraQuest variable speed Machinery Fault Simulator (MFS) was used to generate both normal operation $(N O)$ and faulty condition data. The simulation stand (Fig. 1) comprised 1 HP variable speed motor driving a shaft-rotor component via coupling supported with two sets of ball bearings. The $M F S$ is outfitted with three-axis accelerometer and a tachometer that were connected to a National Instruments $D A Q$ System.

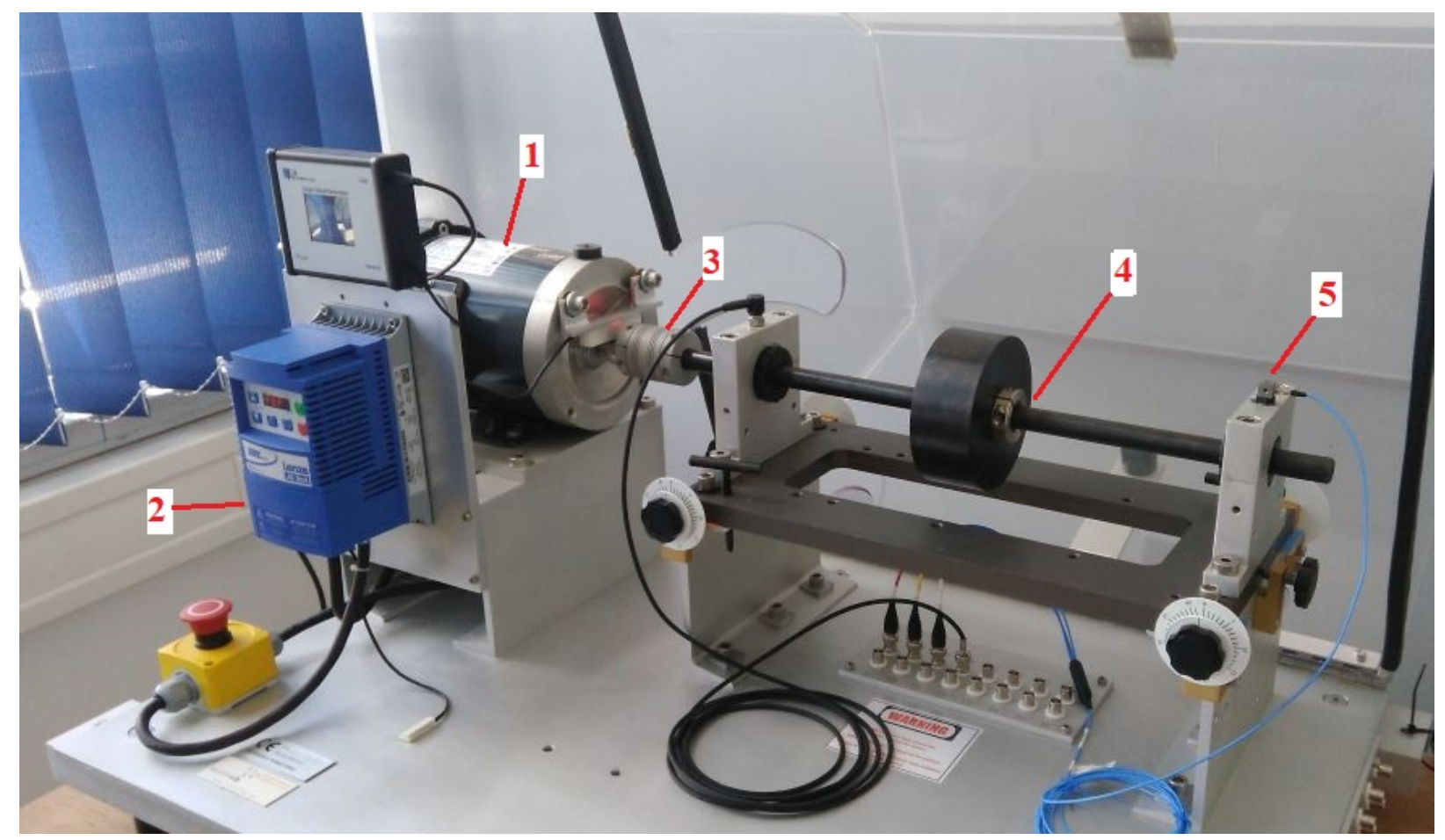

Fig. 1. Fault simulator: 1 -three-phase induction motor, 2 -variable speed motor drive, 3 -clutch, 4 - main shaft with load, 5 - three-axis accelerometer

Three-axis accelerometer was mounted on the bearing housing on the shaft side opposite of the motor position. The sampling frequency was set to $6.4 \mathrm{kHz}$, while revolving speed during the 
experiment was $1500 \mathrm{rpm}$. Vibration signals in three directions $(\mathrm{X}, \mathrm{Y}, \mathrm{Z})$ were acquired when the system operated under normal condition $(N O)$ and faulty conditions $(U N)$. There were four faulty conditions simulated: slant rotor $(S R)$, eccentric rotor $(E R)$, unbalanced rotor without additional load $(U R)$ and unbalanced rotor with additional load $3 \mathrm{~kg}$ along $\mathrm{Z}$ axis $(U R A L)$. Operation under normal conditions was interpreted as operating of the rotating subsystem remaining in ability state while operation under any of faulty conditions was interpreted as operating of the rotating subsystem remaining in inability state.

Each vibration sample comprising 6400 values was stored as a separate vibration signal. The signals acquired for each operation condition were divided into two groups: learning and testing data sets. The learning data set consisted of 926 vibration signals (NO:600; SR:75;ER:75; UR:113; $U R A L: 113)$ and testing data set consisted of 274 vibration signals $(N O: 150 ; S R: 25 ; E R: 25 ; U R: 37$; $U R A L: 37)$.

\section{Reliability states spaces formulation}

The states spaces formulation was accomplished using the vibration signals belonging to the learning set. For each signal for each axis, separately 16 characteristics were calculated according to the following list $[6,15]$ :

$$
\begin{aligned}
& {\left[v s_{i}\right]=\int_{t_{0}}^{t_{k}} v s_{i}(t) d t,} \\
& \left\langle v s_{i}\right\rangle=\frac{1}{t_{k}-t_{0}} \int_{t_{0}}^{t_{k}} v s_{i}(t) d t, \\
& E_{v s i}=\int_{t_{0}}^{t_{k}} v s_{i}^{2}(t) d t \\
& P_{v s i}=\frac{1}{t_{k}-t_{0}} \int_{t_{0}}^{t_{k}} v s_{i}^{2}(t) d t, \\
& \overline{m_{v s i}^{1}}=\int_{t_{0}}^{t_{k}} t \cdot v s_{i}(t) d t, \\
& \overline{m_{v s i}^{2}}=\int_{t_{0}}^{t_{k}} t^{2} \cdot v s_{i}(t) d t, \\
& {\left.\overline{\left(t-\overline{m_{v s i}}\right.}\right)}^{1}=\int_{t_{0}}^{t_{k}}\left(t-\overline{m_{v s i}}\right) \cdot v s_{i}(t) d t, \\
& \overline{\left(t-\overline{m_{v s i}}\right)^{2}}=\int_{t_{0}}^{t_{k}}\left(t-\overline{m_{v s i}}\right)^{2} \cdot v s_{i}(t) d t, \\
& \overline{t_{v s i}^{1}}=\frac{\int_{t_{0}}^{t_{k}} t \cdot v s_{i}(t) d t}{\int_{t_{0}}^{t_{k}} v s_{i}(t) d t},
\end{aligned}
$$




$$
\begin{aligned}
& \overline{t_{v s i}^{2}}=\frac{\int_{t_{0}}^{t_{k}} t^{2} \cdot v s_{i}(t) d t}{\int_{t_{0}}^{t_{k}} v s_{i}(t) d t} \\
& \overline{\left(t-\overline{t_{v s i}}\right)^{1}}=\frac{\int_{t_{0}}^{t_{k}}\left(t-\overline{t_{v s i}}\right) \cdot v s_{i}(t) d t}{\int_{t_{0}}^{t_{k}} v s_{i}(t) d t}, \\
& \overline{\left(t-\overline{t_{v s i}}\right)^{2}}=\frac{\int_{t_{0}}^{t_{k}}\left(t-\overline{t_{v s i}}\right)^{2} \cdot v s_{i}(t) d t}{\int_{t_{0}}^{t_{k}} v s_{i}(t) d t}, \\
& \overline{t_{v s i}{ }^{2}}=\frac{\int_{t_{0}}^{t_{k}} t \cdot v s_{i}^{2}(t) d t}{\int_{t_{0}}^{t_{k}} v s_{i}^{2}(t) d t} \\
& \sigma_{v s i^{2}}^{2}=\frac{\int_{t_{0}}^{t_{k}}\left(t-\overline{t_{v s i^{2}}}\right)^{2} v s_{i}^{2}(t) d t}{\int_{t_{0}}^{t_{k}} v s_{i}^{2}(t) d t} \\
& \Delta t_{v s i}=\frac{\int_{t_{0}}^{t_{k}} v s_{i}(t) d t}{v s_{i}(0)}, \\
& \Delta T_{v s i}=\sqrt{\frac{\int_{t_{0}}^{t_{k}}\left(t-\overline{t_{v s i}}\right)^{2} v s_{i}^{2}(t) d t}{\int_{t_{0}}^{t_{k}} v s_{i}^{2}(t) d t}},
\end{aligned}
$$

where:

$v s_{i} \quad-i$-th recorded vibration signal,

$t_{0} \quad-$ the time of the beginning of the signal $v s$,

$t_{k} \quad$ - the time of the end of the signal vs,

$\left[v s_{i}\right]$ - integral of signal,

$\left\langle v s_{i}\right\rangle$ - mean value of signal,

$E_{v s i}$ - energy of signal,

$P_{v s i}$ - medium power of signal, 
$\overline{m_{v s i}^{x}}$ - simple moment of $x$ order,

$\overline{\left(t-\overline{m_{v s i}}\right)^{x}}$ - central moment of $x$ order,

$\overline{t_{v s i}^{x}} \quad$ - normalized simple moment of $x$ order,

$\overline{\left(t-\overline{t_{v s i}}\right)^{x}}$ - normalized central moment of $x$ order,

$\overline{t_{v s i^{2}}}$ - abscissa of the signal square gravity centre,

$\sigma_{v s i^{2}}^{2}$ - variance of the signal square,

$\Delta t_{v s i}$ - equivalent diameter of signal,

$\Delta T_{v s i}$ - mean width of signal.

Subsequently, for each learning group of vibration signals distinguished for ability state $(N O)$, different simulated inability states $(S R, E R, U R, U R A L)$ and all inability states $(U N)$ for each axis separately mean value and standard deviation of values of each characteristic (1-16) were calculated.

On the basis of the former authors studies [12] it was decided that the characteristic is concentrated if standard deviation $(\sigma)$ of the characteristic value $(D)$ in a group $(V S)$ is lower than $15 \%$ of the mean value (17).

$$
\sigma_{D(V S)} \leq \bar{D}(V S) \cdot 0.15
$$

where:

$D(V S)$ - the characteristic of the vibration signal,

$V S \quad$ - the group of the vibration signals.

In Tab. 1 the results of the concentration analysis of the characteristics are presented. In the Tab. 1 means concentrated and 0 not concentrated characteristic.

Moreover, if the characteristic was concentrated one and the absolute value of the difference of the characteristic mean value for signals from the group of ability states $(N O)$ and mean values of the characteristic for signals from each group of inability states (UN) was higher than the sum of standard deviations of the signals characteristics for analysed groups (18) the characteristic was taken into consideration as a characteristic uniquely identifying the reliability state

$$
\sigma_{D\left(V S_{I A}\right)}+\sigma_{D\left(V S_{A}\right)} \leq\left|\bar{D}\left(V S_{I A}\right)-\bar{D}\left(V S_{A}\right)\right|,
$$

where:

$D(V S)$ - the characteristic of the vibration signal,

$V S_{I A}$ - the group of the vibration signals for inability states,

$V S_{A} \quad$ - the group of the vibration signals for ability states.

Similarly, if the characteristic was concentrated one and the absolute value of the difference of the characteristic mean value for signals from the group of the selected inability state $(S R, E R, U R$, $U R A L)$ and mean values of the characteristic for signals from remaining group of inability states was higher than the sum of standard deviations of the signals characteristics for analysed groups (18) the characteristic was taken into consideration as a characteristic uniquely identifying the type of the inability state (type of failure).

As a result of the performed studies two states spaces were defined. The first of them was $R^{7}$ reliability states space $(R S S)$. The dimensions of the $R S S$ space were the characteristics uniquely identifying the reliability state $\mathrm{X}: 1 ; \mathrm{X}: 2 ; \mathrm{X}: 5 ; \mathrm{X}: 6 ; \mathrm{Z}: 1 ; \mathrm{Z}: 2 ; \mathrm{Z}: 5$ (X and $\mathrm{Z}$ are the vibrations axis; number is the characteristic according to the equations numbers in the article). The second one was $R^{4}$ inability states space (ISS). The dimensions of the ISS space were the characteristics uniquely identifying the type of the inability state $\mathrm{X}: 3 ; \mathrm{X}: 4$; Y:3; Y:4. 
Tab. 1. The results of the concentration analysis of the characteristics

\begin{tabular}{|c|c|c|c|c|c|c|c|c|c|c|c|c|c|c|c|c|}
\hline Axis & \multicolumn{16}{|c|}{$X$} \\
\hline Ch-k & \multirow[t]{2}{*}{1} & \multirow[t]{2}{*}{2} & \multirow[t]{2}{*}{3} & \multirow[t]{2}{*}{4} & \multirow[t]{2}{*}{5} & \multirow[t]{2}{*}{6} & \multirow[t]{2}{*}{7} & \multirow[t]{2}{*}{8} & \multirow[t]{2}{*}{9} & \multirow[t]{2}{*}{10} & \multirow[t]{2}{*}{11} & \multirow[t]{2}{*}{12} & \multirow[t]{2}{*}{13} & \multirow[t]{2}{*}{14} & \multirow[t]{2}{*}{15} & \multirow[t]{2}{*}{16} \\
\hline Group & & & & & & & & & & & & & & & & \\
\hline $\mathrm{NO}$ & 1 & 1 & 0 & 0 & 1 & 1 & 0 & 1 & 1 & 1 & 1 & 1 & 1 & 1 & 0 & 1 \\
\hline SR & 1 & 1 & 1 & 1 & 1 & 1 & 0 & 0 & 1 & 1 & 1 & 1 & 1 & 1 & 0 & 1 \\
\hline ER & 1 & 1 & 1 & 1 & 1 & 1 & 0 & 0 & 1 & 1 & 1 & 1 & 1 & 1 & 0 & 1 \\
\hline UR & 1 & 1 & 1 & 1 & 1 & 1 & 1 & 0 & 1 & 1 & 1 & 1 & 1 & 1 & 0 & 1 \\
\hline URAL & 1 & 1 & 1 & 1 & 1 & 1 & 1 & 0 & 1 & 1 & 1 & 1 & 1 & 1 & 0 & 1 \\
\hline UN & 1 & 1 & 0 & 0 & 1 & 1 & 0 & 0 & 1 & 1 & 1 & 1 & 1 & 1 & 0 & 1 \\
\hline Axis & & & & & & & & & $Y$ & & & & & & & \\
\hline NO & 0 & 0 & 1 & 1 & 0 & 0 & 0 & 0 & 0 & 0 & 0 & 0 & 1 & 1 & 0 & 1 \\
\hline SR & 0 & 0 & 1 & 1 & 0 & 0 & 0 & 0 & 1 & 0 & 1 & 1 & 1 & 1 & 0 & 1 \\
\hline ER & 0 & 0 & 1 & 1 & 0 & 0 & 0 & 0 & 1 & 1 & 1 & 1 & 1 & 1 & 0 & 1 \\
\hline UR & 0 & 0 & 1 & 1 & 0 & 0 & 0 & 0 & 0 & 0 & 0 & 0 & 1 & 1 & 0 & 1 \\
\hline URAL & 0 & 0 & 1 & 1 & 0 & 0 & 0 & 0 & 0 & 0 & 0 & 0 & 1 & 1 & 0 & 1 \\
\hline UN & 0 & 0 & 0 & 0 & 0 & 0 & 0 & 0 & 0 & 0 & 0 & 0 & 1 & 1 & 0 & 1 \\
\hline Axis & & & & & & & & & $\mathrm{Z}$ & & & & & & & \\
\hline $\mathrm{NO}$ & 1 & 1 & 1 & 1 & 1 & 1 & 0 & 0 & 1 & 1 & 1 & 1 & 1 & 1 & 0 & 1 \\
\hline SR & 1 & 1 & 1 & 1 & 1 & 1 & 0 & 1 & 1 & 1 & 1 & 1 & 1 & 1 & 0 & 1 \\
\hline ER & 1 & 1 & 1 & 1 & 1 & 1 & 1 & 0 & 1 & 1 & 1 & 1 & 1 & 1 & 0 & 1 \\
\hline UR & 1 & 1 & 1 & 1 & 1 & 1 & 1 & 0 & 1 & 1 & 1 & 1 & 1 & 1 & 0 & 1 \\
\hline URAL & 1 & 1 & 1 & 1 & 1 & 1 & 0 & 0 & 1 & 1 & 1 & 1 & 1 & 1 & 0 & 1 \\
\hline $\mathrm{UN}$ & 1 & 1 & 1 & 1 & 1 & 1 & 1 & 0 & 1 & 1 & 1 & 1 & 1 & 1 & 0 & 1 \\
\hline
\end{tabular}

\section{Rotating system inability states identification}

In both defined spaces ( $R S S$ and $I S S$ ) the vibration signals are expressed as points determined by the values of characteristics - dimensions of the space. The mean values of the characteristics of learning groups also define points in the space. In this way for $N O$ group of learning signals in $R S S$ space the point of the ability states was defined. Similarly, in $R R S$ space for $S R, E R, U R$ and $U R A L$ groups of learning signals the points of specified inability states were defined. Simultaneously, in $I S S$ space, the mean values of the characteristics - the dimensions of this space for $S R, E R, U R$ and $U R A L$ groups of learning signals determined the points of specific types of inability states. To assure the same influence of each characteristic on the identification process all values were transformed according to formula (19)

$$
D_{T}=\frac{D}{\max (D(V S))} \cdot 100
$$

where:

$D(V S)$ - the characteristic of the vibration signal,

$D \quad$ - the value of the characteristic,

$D_{T} \quad$ - the value of the characteristic after transformation [\%].

Subsequently, in each space, the Euclidian distances between the points enumerated above and the points determined for each vibration signal from testing groups (NOT, SRT, ERT, URT, $U R A L T)$ were calculated. If the distance between the point of $R S S$ space determined for analysed signal and the point of the ability states $N O(R S S)$ was smaller than every distances between that point and $S R(R S S), E R(R S S), U R(R S S)$ and $U R A L(R S S)$ points then the signal was identified as 
registered on rotating subsystem remaining in ability state (no failure). Otherwise, the analysed testing vibration signal was identified as signal registered on rotating subsystem remaining in inability state (operation with failure).

If the signal was classified as a signal registered on rotating subsystem remaining in inability state, it was also analysed in ISS space. The signal was identified as a signal recorded on rotating subsystem remaining in specified inability state if the distance between the point of ISS space determined for analysed vibration signal (from testing groups) and the point of ISS space determined for one of the considered inability states $(S R, E R, U R, U R A L)$ is the smallest one. The results of the performed identification are presented in Tab. 2.

Tab. 2. The results of the identification process

\begin{tabular}{|c|c|c|c|c|c|}
\hline \multicolumn{6}{|c|}{ Identification in RSS space } \\
\hline $\begin{array}{l}\text { Group of testing } \\
\text { signals }\end{array}$ & \multicolumn{2}{|c|}{$\begin{array}{c}\text { Identified } \\
\text { as ability state }\end{array}$} & \multicolumn{2}{|c|}{$\begin{array}{c}\text { Identified } \\
\text { as inability state } \\
\end{array}$} & $\begin{array}{c}\text { Correctness of reliability state } \\
\text { identification [\%] }\end{array}$ \\
\hline NOT & \multicolumn{2}{|c|}{148} & \multicolumn{2}{|c|}{2} & 98.7 \\
\hline SRT & \multicolumn{2}{|c|}{0} & \multicolumn{2}{|c|}{25} & 100 \\
\hline ERT & \multicolumn{2}{|c|}{0} & \multicolumn{2}{|c|}{25} & 100 \\
\hline URT & \multicolumn{2}{|c|}{0} & \multicolumn{2}{|c|}{37} & 100 \\
\hline URALT & \multicolumn{2}{|c|}{1} & \multicolumn{2}{|c|}{36} & 97.3 \\
\hline \multicolumn{6}{|c|}{ Identification in ISS space } \\
\hline $\begin{array}{l}\text { Group of testing } \\
\text { signals }\end{array}$ & $\begin{array}{l}\text { Identified } \\
\text { as SR }\end{array}$ & $\begin{array}{l}\text { Identified } \\
\text { as ER }\end{array}$ & $\begin{array}{l}\text { Identified } \\
\text { as UR }\end{array}$ & $\begin{array}{l}\text { Identified } \\
\text { as URAL }\end{array}$ & $\begin{array}{l}\text { Correctness of inability state } \\
\text { type identification [\%] }\end{array}$ \\
\hline SRT & 25 & 0 & 0 & 0 & 100 \\
\hline ERT & 0 & 25 & 0 & 0 & 100 \\
\hline URT & 0 & 0 & 37 & 0 & 100 \\
\hline URALT & 0 & 0 & 0 & 36 & 100 \\
\hline
\end{tabular}

\section{Summary and conclusions}

The research presented in the article considered reliability states of the rotating subsystems. In order to identify ability and specified inability states the experimental tests were accomplished. During the tests, vibration signals were recorded. Dividing the recorded signals into learning and testing sets and calculating several characteristics of the signals the reliability states space and inability states space were formulated. The spaces were used in proposed classification method to identify the reliability state of the rotating subsystems and to identify the type of the failure in case of the inability state occurrence. Subsequently, the effectiveness of the described identification method was checked using the testing signals set. The tests proved pretty high accuracy of the method. The ability/inability state was correctly identified in more than $99 \%$ and the type of the inability state was identified correctly in $100 \%$. On the basis of the results of the executed tests, it was stated that the proposed identification method is precise enough to be the object of further industrial research.

It is planned to continue the studies in the field of the reliability states identification of the rotating subsystems. The next step of the tests will be the analysis of the identification method accuracy under industrial conditions were different sources of noise can be present. Additionally, the method will be tested using different types of inability states not present in the learning signals set.

\section{References}

[1] Antoni, J., Cyclic spectral analysis of rolling-element bearing signals: Facts and fictions, Journal of Sound and Vibration, Vol. 304, pp. 497-529, 2007. 
[2] Girtler, J., The semi-Markov model of the process of appearance of sea-going ship propulsion system ability and inability states in application to determining the reliability of these systems, Polish Maritime Research, Vol. 20, pp. 18-24, 2013.

[3] Grządziela, A., Musiał, J., Muślewski, Ł., Pająk, M., A method for identification of noncoaxiality in engine shaft lines of a selected type of naval ships, Polish Maritime Research, Vol. 22, pp. 65-71, 2015.

[4] Grządziela, A., Muślewski, Ł., High quality simulation of the effects of underwater detonation impact, Journal of Vibroengineering, Vol. 15, Iss. 1, pp. 106-113, 2013.

[5] Gurr, C., Rulfs, H., Influence of transient operating conditions on propeller shaft bearings, Journal of Marine Engineering and Technology, No. 12, pp. 3-7, 2008.

[6] Izydorczyk, J., Pionka, G., Tyma, G., Theory of Signals. Introduction 2nd Edition-Corrected and Amended, Helion, Gliwice 2006.

[7] Kostek, R., Landowski, B., Muślewski, Ł., Simulation of rolling Bering vibration in diagnostics, Journal of Vibroengineering, Vol. 17, Iss. 8, 2015.

[8] Lal, M., Riwari, R., Multi-fault identification in simple rotor-bearing-coupling systems based on forced response measurements, Mechanism and Machine Theory, Vol. 51, pp. 87-109, 2012.

[9] Li, B., Mo-Yuen, C., Yodyium, T., et al., Neural-network-based motor rolling bearing fault diagnosis, IEEE Transactions on Industrial Electronics, Vol. 47 (5), pp. 1060-1069, 2000.

[10] Molland, A. F., The Maritime Engineering Reference Book, A Guide to Ship Design, Construction and Operation, Butterworth-Heinemann, 2011.

[11] Muślewski, Ł., Evaluation Method of Transport Systems Operation Quality, Polish Journal of Environmental Studies, Vol. 18, No. 2A, Olsztyn 2009.

[12] Muślewski, Ł., Pająk, M., Grządziela, A., Musiał, J., Analysis of vibration time histories in the time domain for propulsion systems of minesweepers, Journal of Vibroengineering, Vol. 17, Iss. 3, pp. 1309-1316, 2015.

[13] Qiu, H., Lee, J., Lin, J., et al., Wavelet filter-based weak signature detection method and its application on rolling element bearing prognostics, Journal of Sound and Vibration, Vol. 289, pp. 1066-1090, 2006.

[14] Ruqiang, Y. R., Gao, R. X., Chen, X., Wavelets for fault diagnosis of rotary machines: A review with applications, Signal Processing, Vol. 96, pp. 1-15, 2014.

[15] Szabatin, J., Signal Theory Fundamentals, WKŁ, Warszawa 2007.

[16] Woropay, M., Landowski, B., Neubauer, A., Controlling reliability in the transport systems, B.P.E.-WIEM, Bydgoszcz - Radom 2004.

[17] Woropay, M., Muślewski, Ł., Quality in a systemic approach, ITeE, Radom 2005.

[18] Zieliński, T. P., Digital Processing of Signals. From theory to practice, WKt, Warszawa 2009. 